\title{
On or Off the Slate: University Library E-Reserve Supports Web-Based Learning
}

\section{Ophelia Cheung}

Ryerson University

Cheung, O. (2005). On or off the slate: University library E-Reserve supports web-based learning. In R. Kwan \& J. Fong (Eds.), Web-Based Learning: Technology and Pedagogy, (pp. 23-28).

doi:10.1142/9789812701664 0003

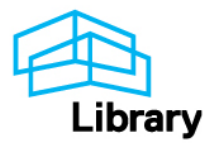




\title{
ON OR OFF THE SLATE: UNIVERSITY LIBRARY E-RESERVE SUPPORTS WEB-BASED LEARNING
}

\author{
OPHELIA CHEUNG \\ Ryerson University Library \\ Toronto, Ontario, Canada
}

\begin{abstract}
Ryerson University Library in Toronto, Canada, embarked on an E-Reserve pilot project in 2004, providing electronic links to journal articles and scanned documents for course readings. Insufficient time allowed by faculty for copyright clearance, excessive copyright cost and the difficulty of achieving a single sign-on by users to access eReserve in Blackboard, the University's courseware, were the major issues. Despite setbacks, E-Reserve continued to undertake innovative projects, using the new E-Reserve module in Blackboard to integrate course readings with faculty course pages, utilizing SFX open linking to connect citations to full-text articles, and experimenting with Web streaming of videos in Blackboard.
\end{abstract}

\section{E-Reserve in University Libraries}

The Internet has increased university faculty and students' access to a myriad of resources outside the walls of the library. Traditional Library services, including Print Reserve, are not flexible enough to meet the needs of the current group of faculty and students, particularly with the increase in "distributed learning" in universities. Like many other libraries, Ryerson Library has re-thought and redefined its services in relationship to the educational needs of its users. An electronic Reserve system, providing a virtual repository for copyright-cleared digitized course readings, available remotely $24 / 7$, was a recent step to keep up with student and faculty demand.

Ryerson University, in Toronto, Ontario, Canada, is a leading centre of career-focused education, offering more than 40 undergraduate and graduate programs, with over 20,000 FTE (full-time equivalent students), and with an ever-growing Distance Education (DE) department. E-Reserve service is especially advantageous for DE students and Web-delivered courses. Users do not have to come on campus during Library opening hours to borrow short-term loan materials from Print Reserve, and worry about fines if they cannot return by the due date or time allowed. Print Reserve keeps only a limited number of copies for borrowing but E-Reserve offers multiple access and simultaneous use. 
E-Reserve has been in existence since the early 1990s, and an estimated 250 E-Reserve systems were in production in the United States in 1999. ${ }^{1}$ In Canada, and in the province of Ontario, the libraries we surveyed in 2002/3 were mostly in their third or fifth years of E-Reserve, but some did not go beyond linking to full-text articles from licensed databases, due to the extra cost and work of obtaining copyright permission for scanning documents. Ryerson Library began e-linking in 2003 at faculty requests. New personnel and a new administrative team structure allowed us to embark on a more ambitious E-Reserve pilot project in 2004. ${ }^{2}$ In 2004, we became more proactive, checking all reserve requests against our Library's subscribed databases and automatically linking the citations to full-text articles wherever available. No duplicate back-ups in paper format were kept in Print Reserve. We also, for the first time, sought copyright permission for materials for which we did not have digital rights (e.g. book chapters), before scanning them on E-Reserve.

When I took on the E-Reserve responsibility in late 2003, I conducted an extensive research on E-Reserve operations in North America, including best practices and case studies. ${ }^{3}$ I was assisted by the Copyright Lead Hand Technician, a newly created staff position for E-Reserve. We learned from others that copyright and systems support were major concerns. The time for copyright clearance ranged from weeks to months. Rights holders could be difficult to locate. There were long waiting periods for responses, and occasionally no responses. The average cost was Can $\$ 30$ to $\$ 90$ per item per course per year. However, some publishers charged a few hundred dollars per item. Who paid the cost - the Department, Library or students, was a major decision. The choice of an E-Reserve system was another issue. Ideally, the system should be userfriendly for students, flexible enough for the Library to restrict access to a course or group, if required by rights holders, and robust enough for tracking statistics. The lessons learned from other E-Reserve operations helped us steer away from anticipated roadblocks but we were not immune to new challenges, some of which forced us to re-assess the direction of the pilot project.

\section{Lessons Learned}

\subsection{Copyright Issues}

Although we emphasized on our Web site that we discouraged digital course packs due to the cost and time for copyright clearance, the very first request from $\mathrm{DE}$, our targeted user group for the pilot project, was a course pack of 29 readings, mostly book chapters. The copyright cost would amount to 
approximately Can $\$ 2,500$ to digitize the chapters for use in three semesters. Eventually, DE proposed seeking administrative and financial approval in the following year for a special student levy to defray such cost. We had better luck with subsequent requests. We only turned down a few faculty requests because the copyright fees were too expensive for our small E-Reserve budget from Library funds.

Almost $50 \%$ of the faculty E-Reserve requests were not completed. One major reason was faculty had not allowed sufficient lead-time for seeking copyright permissions. Some were mistaken in thinking that materials used in an education setting were "exempted" from copyright. Some thought that the permissions obtained by the University Bookstore to compile print course packs for sale to students were transferable to digital course delivery. For those who attempted to create their own links to library databases in their Web course pages, they were not aware that the URL (Uniform Resource Locator) of web sites might break because they were not created to be "persistent" (also known as stable, durable, constant or static URL). What we could have done better was to step up our education of faculty users. We should have made sure they understood fully the copyright implications - the time and cost involved, and the alternatives available (e.g. Print Reserve or print course packs). Our Web page and FAQ may not be effective enough. We should tap the resources of faculty listserv, faculty conferences, new faculty orientations, workshops by librarians and promotion through subject librarians.

Another complication was created by our collaborative programs with other academic institutions. Due to database licensing agreements, access is limited to users in our university community. Some faculty would insist on posting materials only for Ryerson students and asked other students in the collaborative program to access the databases directly, if available at their home institutions. Others abandoned the E-Reserve access altogether, which was unfortunate. While we cannot do much with licensing agreements, we might be able to warn faculty in advance of these complications so that they consider alternatives, such as resorting to course packs.

\subsection{System Issues}

We had looked at how other libraries chose their E-Reserve systems. ${ }^{4}$ In the end, we decided on utilizing the Millenium Media Management module in our integrated library system to manage E-Reserve files. The module allows libraries to share media files with its patrons (e.g. WORD, PDF, TXT, Powerpoint), sounds, movies, HTML files, URLs and images (e.g. jpeg, gif, tiff). Keeping E- 
Reserve part of the integrated library system has the advantage of easier searching and transferring of data within the system, and staff training. However, we had to compromise our local needs. The publisher codes in Media Management have the function of tracking E-Reserve usage for the purpose of paying royalties, if required. Nevertheless, to turn that code on, students on campus will have to authenticate once before accessing library resources, and twice if they log-on from off-campus through the proxy server. The code was never used for the obvious reason of inconvenience to users, and we never obtained usage statistics for E-Reserve access.

The Library authentication presented another obstacle to a single sign-on for Blackboard users. E-Reserve was initially offered only via the Library catalogue. Students could look up course readings by course codes or names of instructors. However, DE courses were mostly delivered on Blackboard, a courseware for faculty and students to deliver lecture notes, complete assignments, conduct virtual discussions and share files and resources. DE had repeatedly enquired why students accessing from home had to go through a library authentication after they had logged-on to Blackboard with their passwords. The same passwords were used for e-mail and lab accounts but not for library authentication. The Systems Librarian in the Borrower Services Team (of which E-Reserve is part) explained that single-sign-on is a complex issue. Innovative Interfaces Inc. (III), our integrated library system vendor, has made some progress, such as introducing a new External Patron Verification package using LDAP (Lightweight Directory Access Protocol) in the new Silver release, which can be used to validate library patrons against an external LDAP server. However, it cannot be used to authenticate in the reverse mode i.e. Blackboard patrons could not authenticate against the Library's patron database. A workaround created by some libraries might involve the creation of PHP scripts to link the student information system with a portal server, a web server, and the Library server. Custom CPIP connections would be required and the student information system might have to be compatible with either Oracle or LDAP. Without significant support in programming and funding, it seems that we might have to wait until III, our systems vendor, develops its own solution to link to the campus portal.

Meanwhile, faculty told us that students accessing from home had to log-on several times to move between E-Reserve files. These students might have closed their browsers or exited Blackboard unnecessarily, or used some older versions of Netscape, not compatible with Blackboard. What we could have done was to advise faculty in advance to link their Web pages to a 
Troubleshooting Guide in the Library Web Page for tips on remote access from home.

\section{New Initiatives to Improve E-Reserve}

Despite the above setbacks, we have made progress in E-Reserve. 33 documents for 6 different courses were scanned in 2004 after clearing copyright, and 18 documents scanned in the first three months of 2005. Links to licensed databases have gone up by 50\%, from 316 links in 2003 to 474 links in 2004. The Nursing Department, in particular, has switched from using print course packs to EReserve, as they rely, almost exclusively, upon our licensed databases.

In early 2005, less than a year since we started our pilot project, we undertook other pilot projects to anticipate demands and improve E-Reserve service. In January, we partnered with DMP (Digital Media Projects Office, the University department providing assistance in the use and production of multimedia technologies for e-teaching and e-learning), to test E-Reserve in the new Blackboard release. Previously, for Blackboard faculty users, we e-mailed them the durable links for incorporation in their course pages. In the new Blackboard System, the Library will create links and upload reserve files into Blackboard. DMP will still be the system administrator and provide training to faculty wanting to create course pages to access E-Reserve from within Blackboard. Integrating E-Reserve with Blackboard is undoubtedly convenient for student users of courses delivered in Blackboard. The controlled access in Blackboard also provides more efficient copyright control, especially if the rights holders require restricted access to scanned documents. Some workflow issues remained. As long as there are courses that are not Blackboard-based, the Library has to maintain library catalogue access to E-Reserve files for nonBlackboard users.

In April 2005, we tested another course using the new Blackboard release and, in addition, employing SFX links, which are vendor-independent, to connect citations to full-text articles. SFX is the link server from Ex Libris. It uses the OpenURL standard for interoperability between information resources and allows for localization in an open linking environment. Apart from the relative ease of using OpenURL Connector for locating the databases that contain the journal citations and generating E-Reserve links, we hope that the central maintenance of SFX links by our Collections Team in the Library will reduce the incidences of broken links, which leave students with only a citation or an abstract when they want to see a full-text article. These were often caused by changes in publishers' activities (e.g. mergers and acquisitions) or journal 
content in the aggregator databases. We used to make a direct link to one single database, but SFX offers a menu of multiple database options, so users will have more choice in the event of a broken link. The SFX screen will also provide a Library branding presence in Blackboard. We will not lose the Library identity entirely in the campus portal. We are not the first in integrating E-Reserve with Blackboard but we may be a pioneer in the application of SFX links to EReserve.

In April 2005, E-Reserve also worked with DMP to digitize videos for streaming in Blackboard. The Audio Visual (AV) Librarian in our Borrower Services Team is exploring a site license agreement with a major Canadian distributor of educational videos for streamed content and the acquisition of the digital rights for a streamed Nursing video series. If successful, the Webstreaming solution in Blackboard will become a breakthrough in the delivery of $\mathrm{AV}$ content, solving the chronic issue of faculty and students competing for access, on-site and off-campus.

\section{Conclusion}

It has been a year since our E-Reserve project was officially launched. The lessons we learned could be useful for other universities planning to start or improve their E-Reserve operations. In the face of changes, we maintain that the right direction to deal with them is to embrace them. Our team structure has anticipated the need for amalgamation of expertise to meet the challenges ahead - systems, copyright, multimedia, publicity and collaboration with diverse user groups within the University. We are well positioned to cope with these issues, central to the successful delivery of E-Reserve in its existing or a revised mode in the future.

\section{References}

1. LU, S., 2001. A model for choosing an electronic reserve system: a preimplementation study at the Library of Long Island University's Brooklyn campus. Journal of Interlibrary Loan, Document Delivery \& Information Supply, 12(2): 25-44.

2. CHEUNG, O. and PATRICK, S., 2004. The gang's all here: team-work and collaboration facilitate E-Reserve for e-learning through the university library. In: E-Learning in Corporate, Government, Healthcare, \& Higher Education Conference Proceedings, pp. 539-542.

[E-Learn World Conference held in Washington, D.C., United States, November, 2004.] 
3. CODY, S.A., PFOHL, D. and BITTNER, S., 2001. Establishing and refining electronic course reserves: a case study of a continuous process. Journal of Interlibrary Loan, Document Delivery \& Information Supply, 11(3): 11-37.

4. PEARCE, L., 2001. Lessons learned: the development of electronic reserves at the University of Calgary. D-Lib Magazine, 7(11). Online. Available: http://www.dlib.org/dlib/november01/pearce/11pearce.html/. 